\title{
PENANDA EMOTIF PARTIKEL JONEGOROAN
}

\author{
Mixghan Norman Antono \\ Universitas Trunojoyo Madura \\ mixghan.norman@trunojoyo.ac.id
}

\begin{abstract}
Abstrak
Penelitian ini merupakan penelitian kualitatif yang dilakukan untuk mengungkapan penanda emotif dari partikel yang digunakan oleh Bahasa Subdialek Jonegoroan. Setidaknya subdialek ini memiliki tujuh partikel, diantaranya: (1) - leh, (2) - je, (3) - jal, (4) - jan, (5) -em dan -nem, (6) nyo, dan (7) -men. . Masing-masing partikel memiliki penanda emotif yang berbeda-beda. Apabila diklasifikasikan, penggunaan partikel pada subdialek Jonegoroan ini berfungsi untuk menandai emotif penegasan, kekecewaan, keberlebihan, kepemilikan, dan pernyatan ingkaran.
\end{abstract}

Kata Kunci: Partikel, Subdialek Jonegoroan, Penanda Emotif.

\section{Abstract}

This research is a qualitative study conducted to reveal the emotive markers of particles used by the Jonegoroan Subdialek Language. At least this subdialect has seven particles, including: (1)leh, (2) -je, (3) -jal, (4) -jan, (5) -em and-nem, (6) -nyo, and (7) -men. . Each particle has a different emotive marker. When classified, the use of particles in the Jonegoroan subdialect serves to mark the emotive affirmation, disappointment, overload, ownership, and statement of the negation

Keywords: Particle, Jonegoroan Subdialek, Emotive Marker.

\section{PENDAHULUAN}

Dalam Kamus Besar Bahasa Indonesia, partikel merupakan kata yang biasanya tidak dapat diderivasikan atau diinfleksikan. Partikel mengandung makna gramatikal namun tidak dengan makna leksikal. Makna leksikal dari sebuah partikel ditentukan oleh kaitannya dengan kata lain dalam suatu frasa. Pada kajian morfologi, dapat diartikan bahwa partikel memiliki kedudukan sebagai morfem terikat yang keberadaannya bergantung pada morfem bebas sebagai penyertanya.

Secara umum, partikel dikelompokkan berdasarkan fungsinya. Dalam bahasa Indonesia setidaknya terdapat lima pengelompokan partikel, diantaranya: (1) Partikel sebagai Preposisi, (2) Partikel sebagai Konjungsi, (3) Partikel sebagai Interjeksi, (4) Partikel sebagai Artikel (Kata Sandang), dan (5) Partikel sebagai Penegas. Namun, pengelompokan ini tidak hanya berlaku pada Bahasa Indonesia saja, tetapi juga pada beberapa bahasa daerah di Indonesia, termasuk bahasa Jawa.

Bahasa Jawa memiliki relik bahasa yang cukup beragam, beberapa subdialek dari dialek ini memiliki kekhasan yang berbeda. Sebagai contoh bahasa Jawa Subdialek Solo dan subdialek Surabayan memiliki cara khas pelafalan meskipun menggunakan dialek yang sama, pun demikian dengan Bahasa Jawa subdialek Jonegoroan (Bojonegoro). Subdilaek Jonegoroan terletak diantara persebaran bahasa Jawa antara Solo dan Surabaya yang memiliki radar perkembangan bahasa yang kuat. Subdialek ini memiliki aksen yang khas berbeda dengan dua subdialek yang menjadi radarnya.

Salah satu penanda subdialek Jonegoroan tampak dari penggunaan partikel yang khas. Setidaknya subdialek ini memiliki tujuh partikel, diantaranya: (1) -leh, (2) -je, (3) jal, (4) -jan, (5) -em dan -nem, (6) -nyo, dan (7) -men. Masing-masing partikel secara emotif memiliki fungsi yang berbeda dalam setiap penggunaannya. Oleh karena itu artikel ini ditulis dengan tujuan menggungkapkan fungi emotif dari partikel-partikel subdialek Jonegoroan ini.

\section{METODE PENELITIAN}

Penelitian ini menggunakan pendekatan kualitatif dengan paradigma fenomenologis/ interpretif. Paradigma fenomenologis/interpretif menjelaskan bagaimana keberadaan manusia 
April 2020 Jurnal Pendidikan Bahasa dan Sastra Indonesia

dalam menginterpretasi dan merasakan realitas (Audifax dalam Mega dan Pramesti, 2015).

Metode penelitian yang digunakan adalah jenis metode wawancara/Interview dan jenis instrumen yang digunakan adalah pedoman wawancara/interview. Suandi (2008) menyatakan wawancara atau interview adalah suatu bentuk komunikasi verbal jadi semacam percakapan yang bertujuan memperoleh informasi. Tipe penelitian studi kasus intrinsik dipilih karena penelitian dilakukan berdasarkan ketertarikan kasus yang akan lebih dipahami guna menginterpretasi permasalahan yang diteliti

\section{ANALISIS DATA TUTURAN}

Setalah dilakukan reduksi data, data tuturan dalam artikel ini akan dibagi berdasarkan dua jenis, yakni data primer dan data sekunder. Kedua jenis data ini pada dasarmya memiliki tingkat generalisasi yang sama, hanya saja karakteristik data tuturan primer yang merupakan data utama akan lebih banyak dimunculkan pada bagian pembahasan.

Sebagaiman telah disampaikan pada bagian pendahuluan, aada tujuh partikel yang digunakan oleh subdialek Jonegoroan sebagai penanda emotif subdialek ini. Partikel ini diantaranya: : (1) -leh, (2) -je, (3) -jal, (4) -jan, (5) - em dan -nem, (6) -nyo, dan (7) -men.

\section{HASIL PEMBAHASAN}

\section{a. Partikel-Leh}

Partikel ini merupakan penanda emotif penegasan dalam pembentukan sebuah kalimat. Penggunaan partikel ini bergantung pada kalimat subversif yang dalam pengejawantahannya dapat berbentuk kalimat larangan, perintah maupun penggungkapan keingintahuan yang dalam.

Contoh: "ning yo ojo ngono leh!"

Kalimat ini memiliki makna larangan yang lebih tegas jika diujarkan menggunakan partikel -leh. Berbeda jika kalimat ini hanya diujarkan tanpa partikel.

\section{b. Partikel -Je}

Sepintas penggunaan partikel ini hampir sama dengan partikel -leh, hanya saja fungsi emotif partikel ini digunakan untuk melakukan penguatan dan pembentukan pernyataan ingkaran (negasi). Berdasarkan fakta sejarahnya, partikel ini muncul berdasarkan kebiasaan berbicara masyarakat Bojonegoro yang mendiami daerah sekitar pinggiran Tuban. Sehingga dapat dikatakan bahawa partikel ini merupakan bentuk akulturasi subdialek Tubanan dan subdialek Jonegoroan.

Contoh:"ora aku je seng ngrusak motorem!"

Pada kalimat ini, partikel -je secara utuh dapat digunakan dalam sebuah kalimat imperative. Kalimat ini sering digunakan sebagai penanda akhir percakapan, dalam artin penutur berharap mitra tutur tidak kembli mencerca dengan berbagai pertanyaan lainnya.

\section{c. Partikel -Jal}

Partikel -Jal mengandung muatan emotif yang cukup dalam akibat pengaruh unsur kekerabtan. Partikel ini akan terasa biasa saja jika diujarkan oleh dua orang yang memiliki tingkat kekerabatan cukup kental. Namun jika dua orang tidak saling mengenal berbicara dengan menggunakan partikel ini, maka akan muncul penanda emotif lain yang cenderung lebih kasar dan kurang sopan.

Emotif yang terkandung dalam partikel ini bergantung pada kondisi emosional penuturnya. Partikel ini dapat memperhalus maupun menegaskan makna sebuah kalimat.

Contoh: "iki piye jal?"

Pada konteks kalimat tersebut, partikel jal secara emotif berfungsi memperhalus makna dari kalimat "iki piye?"

\section{d. Partikel-Jan}

Partikel ini memiliki fungsi emotif untuk mengungkapkan kekaguman juga kekecewaan yang mendalam. Kekaguman yang dimaksud bias digunakan pada benda, manusia, atu bahkan hal yang dianggap abstrak sekalipun.

Contoh: "bocah iku jan ayu tenan!"

Dalam konteks makna, partikel -jan dapat dimaknai sebagai penanda 'sangat' atau 'keterlaluan'. Masyarakat bojongeoro bias menggunakan partikel ini untuk mengungkapkan sesuatu yang mungkin tidak bias dihitung dalam angka atau dikiaskan dalam kata.

\section{e. Partikel-em dan-nem}

Di antara partikel lainnya, mungkin dapat dikatakan bahwa partikel ini memiliki keunikan yang cukup istimewa. Keduanya memiliki penanda emotif yang sama yakni sebagai fungsi kepemilikan. Pembeda sederhana kedua partikel ini adalah bahwa partikel -em digunakan sebagai partikel yang megikuti konstituen silaba tertutup, sedangkan -nem digunakan sebagai partikel dengan menyertai konstituen silaba terbuka. 
Contoh: "iki nggonem to?" "iki wek em to?"

Dua kalimat tersebut memilik makna yang sama, yakni “ini milikmu kan?”. Keduanya dapat digunakan sebagai penanda deklaratif yang menyatakan suatu kepemilikan.

\section{f. Partikel-nyo}

Partikel ini merupakan bentuk abreviasi dari kata genyo [gəңつ]. Genyo calam subdialek Jonegoroan memiliki makna hampir sama dengan "mau dikata apa". Abreviasi yang terjadi pada kata ini tidak begitu jelas sebabnya, namun memang agak sulit jika harus mengujarkan kata 'genyo' pada kerapatan konsonan tertentu.

Dalam subdialek ini, partikel -nyo cenderung didistribusikan pada akhir kalimat sebagai pernyataan penyesalan.

Contoh: "ndah nyo aku seng tibo, wes nangis aku."

Pada contoh kalimat terssebut tidak ada unsur emotif lain, selain penegasan sebuah penyesalan.

\section{g. Partikel -men}

Partikel ini merupakan partikel penegas yang menyatakan sesuatu yang terlalu atau berlebih. Misalnya kuantitas, perilakum hingga pengungkapan kekaguman yang berlebihan. Penggunaan partikel ini sangat dipengaruhi oleh pola intonasi naik-turun penuturnya. Partikel ini bernilai emotif positif apabila diujarkan dengan intonasi turun, namun sebalikanya akan bernilai emotif negative jika diujarkan dengan intonasi meninggi.

\section{SIMPULAN}

Berdasarkan hasil analisis ditemukan bahwa terdapat tujuh partikel dalam subdialek Jonegoroan yang sering digunakan sebagai penanda emotif masyarakat penuturnya. Partikel ini diantaranya: : (1) -leh, (2) -je, (3) -jal, (4) jan, (5) -em dan -nem, (6) -nyo, dan (7) -men. Masing-masing partikel memiliki penanda emotif yang berbeda-beda. Apabila diklasifikasikan, penggunaan partikel pada subdialek Jonegoroan ini berfungsi untuk menandai emotif penegasan, kekecewaan, keberlebihan, kepemilikan, dan pernyatan ingkaran.

\section{REFERENSI}

. Kamus Besar Bahasa Indonesia. (Daring). Tersedia di kbbi.kemdikbud. go.id. Diakses pada tanggal 2 April 2020

Rani, Abdul, dkk. 2006. Analisis Wacana: Sebuah Kajian Bahasa dalam Pemakaian. Malang: Bayumedia Publishing.

Suandi, I.N. 2008. Pengantar Metodologi Penelitian Bahasa. Singaraja: Universitas Pendidikan Ganesha.

Sudaryanto. 1992. Tata Bahasa Baku Bahasa Jawa. Yogyakarta: Duta Wacana University

Press.

Sugiarto, Singgih. 2008. Partikel Fatis Si, Li/Tli/Tuli, Be, Ko, Mbog, Jen/Jan, Nden dalam Bahasa Jawa Dialek banyumas di Purbalingga. Skriosi FIPB UI. 
Volume 5 No. 1 METALINGUA

April 2020 Jurnal Pendidikan Bahasa dan Sastra Indonesia 